\title{
A Folk Theorem for One-Shot Bertrand Games
}

\author{
Michael R. Baye \\ John Morgan \\ Indiana University Princeton University \\ February 1999
}

\begin{abstract}
We show that bounded monopoly profits are essential for the uniqueness of the Bertrand paradox (zero profit) outcome. Otherwise, a folk theorem obtains for one-shot homogeneous product Bertrand games: any positive (but finite) payoff vector can be achieved in a symmetric mixed-strategy Nash equilibrium.

JEL Numbers: D43, C72
\end{abstract}

\section{Introduction}

Every first-year graduate student in economics is taught that when two identical price setting firms produce homogeneous products at constant marginal cost, marginal cost pricing is the unique Nash equilibrium. This result, commonly referred to as the Bertrand paradox, dates back to the nineteenth century. Its originator, Joseph Bertrand (1883), first described the logic underlying the paradox as follows:

"... one of the proprietors will reduce his price to attract buyers to him, and [the] other will in turn reduce his price even more to attract buyers back to him. They will stop undercutting each other in this way, when either proprietor, even if the other abandoned the struggle, has nothing more to gain from reducing his price...[Otherwise], whatever the common price adopted, if one of the owners, alone, reduced his price, he [would], ignoring any minor exceptions, attract all of the buyers, and thus double his revenue if his rivals let him do so." [Translated by Chevaillier in Magnan (1992, p. 649)].

While Bertrand's own reasoning led him erroneously to conclude that there did not exist an equilibrium to this formulation, ${ }^{1}$ it is now generally accepted that in the

\footnotetext{
${ }^{1}$ Bertrand wrote, "There is no solution under this assumption, in that there is no limit to the downward movement [in prices]."
} 
absence of capacity constraints, homogeneous product Bertrand competition leads to marginal cost pricing and (in the absence of fixed costs) zero profits. More formally, Harrington (1989) has shown that the Bertrand paradox (zero profit) outcome is the only equilibrium outcome when firms produce at constant marginal cost and market demand is bounded, continuous, downward sloping, and has a finite choke-price.

In modeling oligopoly markets, it is often convenient to assume that the market demand function is differentiable at each positive price. Examples include the case of unit market demand or, more generally, the case where the elasticity of market demand is constant at all prices. Since these two specifications may be inconsistent with a finite choke-price, it is an open question whether the uniqueness of the Bertrand paradox outcome obtains in these settings. We show that in the absence of a finite choke-price, positive profit equilibria can arise in homogeneous product Bertrand games. In fact, when the absence of a choke-price gives rise to unbounded monopoly profits, a folk theorem obtains for one-shot homogeneous product Bertrand games. That is, any positive (but finite) payoff vector can be achieved in a symmetric Nash equilibrium.

\section{The Folk Theorem}

Consider a market in which a set $N=\{1,2, \ldots n\}$ of $n>1$ identical, risk-neutral firms compete to supply some homogeneous product. Let $\pi(p)$ denote the profit function a monopolist charging a price $p \in \mathcal{P} \subseteq[0, \infty)$ would earn in this market, where $\mathcal{P}$ is a connected set. We assume that there is a minimum price that a monopolist must charge in order to break even in the market; that is, there exists a price $p^{*} \in \mathcal{P}$ such that for all $p \in \mathcal{P}, p<p^{*}$ implies $\pi(p) \leq \pi\left(p^{*}\right)=0$. Let $p^{M} \equiv \arg \sup \{\pi(p)\}$ denote the (possibly infinite) monopoly price, and suppose that $\pi(p)$ is continuous

and strictly increasing on $\left[0, p^{M}\right)$. Since the game is symmetric, it is natural to restrict attention to the case in which all firms have an identical strategy space, $\mathcal{P}$. Thus, $\mathcal{P}^{n}$ denotes the strategy space of the Bertrand game. Each firm simultaneously chooses a price, $p_{i} \in \mathcal{P}$, with the firm charging the lowest price winning the monopoly profits corresponding to that price. In the event of a tie for low price, we assume that each firm has an equal chance of serving the entire market. Thus, if $\left(p_{1}, p_{2}, \ldots, p_{n}\right) \in \mathcal{P}^{n}$ are the prices chosen by the $n$ firms, the profits of firm $i$ are given by:

$$
\pi_{i}\left(p_{1}, p_{2}, \ldots, p_{n}\right)= \begin{cases}\pi\left(p_{i}\right) & \text { if } \quad p_{i}<p_{j}<\infty \forall j \neq i \\ \frac{1}{m} \pi\left(p_{i}\right) & \text { if } i \text { ties } m-1 \text { other firms for low price } \\ 0 & \text { otherwise }\end{cases}
$$

If we let $\Pi=\left(\pi_{1}, \pi_{2}, \ldots \pi_{n}\right)$ denote the vector of these payoff functions, then a homogeneous product Bertrand game is given by $\Gamma\left\langle N, \mathcal{P}^{n}, \Pi\right\rangle$.

We now state our main result. 
Theorem 1 (A One-Shot Folk Theorem) Let $\Gamma$ be a homogeneous product Bertrand game in which $\lim _{p \rightarrow p^{M}} \pi(p) \rightarrow \infty$. Then any $k \in[0, \infty)$ may be achieved as the expected per firm profits in a symmetric mixed-strategy Nash equilibrium of $\Gamma$.

Proof. Since $\pi(p)$ is a strictly increasing, continuous function on $\left[p^{*}, p^{M}\right)$, it follows that for all $k \in[0, \infty), \pi^{-1}(k)$ exists and is strictly increasing in $k$. It follows that

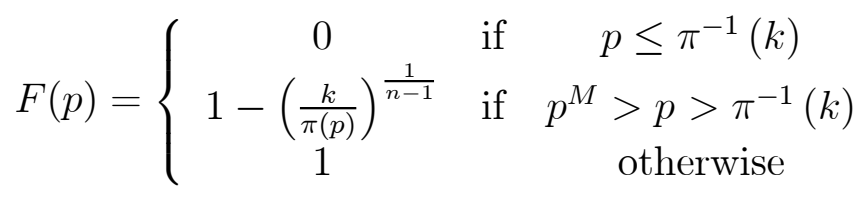

is a well-defined, atomless probability distribution on $\left[\pi^{-1}(k), p^{M}\right)$. Suppose that all $n$ firms select prices at random from $F$. Since $F$ is atomless, firm $i$ sets the lowest price if and only if the other $n-1$ firms set a price above $p_{i}$. Hence the expected profits enjoyed by firm $i$ if it sets a price of $p$ when other firms randomize according to $F$ is

$$
E \pi_{i}=[1-F(p)]^{n-1} \pi(p) .
$$

For $p \in\left[\pi^{-1}(k), p^{M}\right)$ this is constant and equal to $k$ by construction. It does not pay for firm $i$ to price below $\pi^{-1}(k)$, since the firm would win the entire market for certain but earn profits strictly less than $k$. Thus, $F$ constitutes a symmetric mixed-strategy Bertrand-Nash equilibrium in which each firm earns expected profits of $k$.

The equilibrium mixed-strategies balance two opposing forces. By lowering its price, a firm increases the chance of winning the entire market, but reduces the level of profits conditional upon winning. Setting a higher price reduces the chance of winning the entire market, but leads to greater profits conditional upon winning. When monopoly profits are unbounded, one can construct mixed-strategies that allocate sufficient density at each price $p \in\left[\pi^{-1}(k), p^{M}\right)$ to ensure that the rival's expected payoff equals $k$ at that price. By pricing below $\pi^{-1}(k)$, a firm could guarantee itself the entire market, but profits would then be below $k$. The equilibrium mixed strategy employed by each firm eliminates the rival's temptation to lower its price (in an attempt to capture the entire market) by ensuring that its rival has a positive likelihood of earning even greater profits in the event it captures the entire market at a higher price.

The following two examples illustrate the use of this folk theorem.

Example 1 (Hotelling) Two risk-neutral firms produce identical products at zero cost. Market demand is unity for any finite price, and the firm that charges the lowest price gets the entire market. In the event of a tie, each firm has an equal chance of servicing the entire market. Thus, the expected profits of firm $i$ if it charges any price $p_{i} \in[0, \infty)$ when the rival charges $p_{j} \in[0, \infty)$ is given by 


$$
\pi_{i}\left(p_{i}, p_{j}\right)=\left\{\begin{array}{ccc}
p_{i} & \text { if } & p_{i}<p_{j}<\infty \\
\frac{1}{2} p_{i} & \text { if } & p_{i}=p_{j}<\infty \\
0 & & \text { otherwise }
\end{array}\right.
$$

These payoff functions arise in the Hotelling model when the firms are located at the same point in product space. ${ }^{2}$

By the usual reasoning $p_{1}=p_{2}=0$ is the unique pure strategy Nash equilibrium. However, since $\pi(p)=p$ is unbounded, Theorem 1 implies that for every $k \in(0, \infty)$ there also exists a symmetric mixed-strategy Nash equilibrium that is atomless on $[k, \infty)$ in which each firm earns expected profits of $k$ and prices according to the distribution function

$$
F(p)=\left\{\begin{array}{ccc}
0 & \text { if } & p \leq k \\
1-\frac{k}{p} & \text { if } & p>k
\end{array}\right.
$$

over the support $[k, \infty)$. Thus, in addition to the well-known zero-profit pure strategy equilibrium, the Hotelling game also has a continuum of positive profit Nash equilibrium payoffs.

In this example, market demand is perfectly inelastic and marginal cost is zero. One can show that the corresponding Cournot (quantity setting) game also has a continuum of Nash equilibrium payoffs that range from the competitive (zero profit) to the monopoly (infinite profit) level. ${ }^{3}$ One might conjecture that the positive profit equilibria will vanish if market demand is downward sloping and the corresponding Cournot equilibrium is unique. The following example shows that this conjecture is false.

Example 2 (Isoelastic Demand) ${ }^{4}$ Two risk-neutral firms produce identical products at constant marginal cost, $c \geq 0$. There are no capacity constraints, and the market demand curve is given by $D(p)=p^{-\alpha}$, where $\alpha \in\left(\frac{1}{2}, 1\right)$. It is straightforward to verify that for $\alpha \in\left(\frac{1}{2}, 1\right)$, the unique symmetric Cournot equilibrium profits are

\footnotetext{
${ }^{2}$ To see this, set $a=b=\frac{1}{2}$ in the profit function given on page 286 of Gabszewicz and Thisse (1992).

${ }^{3}$ To see this, suppose the Cournot market clears as follows: if $q_{1}+q_{2}=1$, the Walrasian auctioneer chooses an arbitrary $p^{*} \in[0, \infty)$ as the Cournot price (since any price clears the market). If $q_{1}+q_{2} \neq$ 1 , then the auctioneer sets the Cournot price at $p^{*}=0$ (since a market-clearing price does not exist). Given this Walrasian mechanism, if each Cournot firm produced an output of $q_{i}=\frac{1}{2}$ then neither firm would have a unilateral incentive to change output. But with perfectly inelastic aggregate demand, this means that any corresponding Cournot equilibrium price, $p^{*} \in[0, \infty)$ supports this equilibrium, and therefore there exist a continuum of Cournot equilibrium profits that lie in the interval $[0, \infty)$.

${ }^{4}$ This example of positive profit outcomes arising under constant returns to scale has been independently identified by Kaplan and Wettstein (1997).
} 
$\pi_{i}^{*}=\pi^{*}$, where

$$
\pi^{*} \equiv\left(\frac{c}{4 \alpha-2}\right)\left(\frac{c \alpha}{2 \alpha-1}\right)^{-\alpha}>0 .
$$

Under Bertrand competition the profits of firm $i$ are given by

$$
\pi_{i}\left(p_{1}, p_{2}\right)=\left\{\begin{array}{cll}
\left(p_{i}-c\right) p_{i}^{-\alpha} & \text { if } & p_{i}<p_{j}<\infty \\
\frac{1}{2}\left(p_{i}-c\right) p_{i}^{-\alpha} & \text { if } & p_{i}=p_{j}<\infty \\
0 & & \text { otherwise }
\end{array}\right.
$$

By the usual reasoning, the unique pure-strategy Bertrand-Nash equilibrium is $p_{1}^{*}=$ $p_{2}^{*}=c$, and by equation (1) the corresponding Bertrand equilibrium profits are strictly less than profits under Cournot competition. However, since $\pi(p)=(p-c) p^{-\alpha}$ is unbounded, Theorem 1 implies that for every $k \in(0, \infty)$ there also exists a symmetric mixed-strategy Nash equilibrium that is atomless on $\left[\pi^{-1}(k), \infty\right)$ in which each firm earns expected profits of $k>0$.

By choosing $k>\pi^{*}$, the Bertrand duopolists can actually earn profits that exceed the Cournot equilibrium profits! Thus, the uniqueness of the Cournot equilibrium does not imply the Bertrand paradox, nor does it imply that Bertrand firms are doomed to earn lower profits than their Cournot counterparts. The positive profit Bertrand equilibria arise in this example because, when $\alpha<1$, monopoly profits are unbounded. Notice that when $\alpha>1$, Theorem 1 does not apply even though there still does not exist a finite choke price.

\section{Discussion}

The existence of a continuum of positive Nash equilibrium payoffs is reminiscent of folk theorems for infinitely repeated games (see Fudenberg and Maskin, 1986). It turns out that the resemblance between the two results is not simply superficial, and it is useful to compare the forces at work in our folk theorem and examples with those underlying folk theorems for infinitely repeated games. Recall that if a one-shot game has a unique Nash equilibrium, then that equilibrium remains the unique equilibrium even if the game is repeated a finite (but known) number of times. The presence of a known, terminal period leads to the backwards unraveling of any alternative strategies. The folk theorems for repeated games illustrate the power of infinity in economic models: If the game is infinitely repeated, there is no point at which to begin the backward unraveling, and thus a host of other equilibria can be maintained via trigger strategies, provided the discount factor, $\delta$, is sufficiently close to one. Infinitely repeated games entail an infinity of resources changing hands over time, although at each date transactions are finite: firms that conform earn profits, say, of $\pi>0$ each day forever. Notice, however, that continuation payoffs can be made arbitrarily large, since $\sum_{t=0}^{\infty} \delta^{t} \pi$ tends to infinity as $\delta$ tends to 1 . The fact 
that potential continuation payoffs are unbounded allows one to construct incentives (through trigger strategies) that balance a firm's temptation to deviate against the payoffs from conforming to the proposed set of strategies.

Similarly, in our folk theorem the continuum of positive profit mixed-strategy equilibrium profits arise because potential (monopoly) profits are unbounded. This undermines the price undercutting argument in much the same way that an infinite horizon undermines the backward unraveling argument in repeated games. Just as there is no date at which continuation payoffs are bounded in applications of the folk-theorem for infinitely repeated games, in the two examples there is no price that bounds payoffs conditional upon winning the entire market. This destroys the price undercutting argument, and leaves open a continuum of positive-profit mixed strategy equilibria in which realized profits are finite with probability one, but wherein each firm earns positive expected profits of $k>0$.

We conclude by pointing out that our Theorem 1 can also be applied in settings where consumers have a finite choke price, provided firms are uncertain what this price is.

Example 3 (Uncertain Choke-Price) There are $n>1$ risk-neutral firms that produce at zero cost. Market demand is given by $D(p)=p^{-\alpha}$ if $p \leq r$, and zero otherwise. Here, $r>0$ represents the choke-price: if the market price exceeds $r$, demand falls to zero. Firms do not know for certain what $r$ is, but perceive that it is drawn from a Pareto distribution with density $g(r)=\beta / r^{\beta+1}$ on $[1, \infty)$ and corresponding distribution function, $G$.

A firm that sets the lowest price earns the corresponding monopoly profits only if the winning price is below $r$. Hence, conditional on setting the lowest price, firm $i$ 's expected (monopoly) profits are $\pi\left(p_{i}\right) \equiv\left[1-G\left(p_{i}\right)\right] D\left(p_{i}\right) p_{i}=p_{i}^{(1-\alpha-\beta)}$. Firm $i$ 's payoff function in this Bertrand game is therefore

$$
\pi_{i}\left(p_{1}, p_{2}, \ldots, p_{n}\right)=\left\{\begin{array}{lll}
p_{i}^{(1-\alpha-\beta)} & \text { if } \quad p_{i}<p_{j} \forall i \neq j \\
\frac{1}{m} p_{i}^{(1-\alpha-\beta)} & \text { if } i \text { ties } m-1 \text { other firms for low price } \\
0 & & \text { otherwise }
\end{array}\right.
$$

It is routine to verify that this game satisfies the conditions of Theorem 1 when $\alpha+\beta<1$. Thus for every $n>1$ and $k \in(0, \infty)$, there exists a symmetric mixedstrategy Nash equilibrium that is atomless on $\left[k^{1 /(1-\alpha-\beta)}, \infty\right)$ in which each firm's expected profits are $k$. In fact, the following probability distribution comprises such an equilibrium:

$$
F(P)=\left\{\begin{array}{lll}
0 & \text { if } & p \leq k^{1 /(1-\alpha-\beta)} \\
1-\left[\frac{k}{p}\right]^{\frac{-(\alpha+\beta-1)}{n-1}} & \text { if } & p>k^{1 /(1-\alpha-\beta)}
\end{array}\right.
$$


With an uncertain choke-price, for any finite $p \in[0, \infty)$, there is still a positive (but possibly slight) probability that consumers are willing to pay even more for the product. Provided the resulting profits are sufficiently high (as will be the case if $\alpha+\beta<1$ ), then positive profit Bertrand equilibria exist.

This result is similar to folk theorems for finitely repeated games with random terminal periods. That literature shows that if, for any finite stage $T \in\{1,2, \ldots\}$ reached by the firms, there is a sufficiently high probability that the game will continue for another period, then a folk theorem obtains. Thus, the folk theorem can survive in repeated games that terminate in finite time with probability one. Example 3 shows that positive profit equilibria can survive in Bertrand games where the maximum amount consumers will pay is finite with probability one. When one assumes a potentially unbounded stream of resources, as is implicit in the literature on infinitely repeated games, neither trigger strategies nor the repetition of the game is necessary to generate a folk theorem for homogeneous product Bertrand games. 


\section{References}

[1] Fudenberg, D. and E. Maskin, "The Folk Theorem for Repeated Games with Discounting and with Incomplete Information," Econometrica (1986) 54, pp. 533554.

[2] Gabszewicz, J. and J.-F. Thisse, "Location," in Handbook of Game Theory, Volume 1, R. J. Aumann and S. Hart (eds.), Elsevier Science Publishers B.V., 1992, pp. 281-304.

[3] Hotelling, H., "Stability in Competition," Economic Journal (1929) 39, pp. 41-57.

[4] Harrington, J., "A Re-evaluation of Perfect Competition as the Solution to the Bertrand Price Game," Mathematical Social Sciences (1989) 17, pp. 315-328.

[5] Kaplan, T. and D. Wettstein, "Mixed-strategy Equilibria with Constant-Returnsto-Scale Technology under Bertrand Competition," mimeo, Ben-Gurion University, 1997.

[6] Magnan, J., "The 'Cournot-Bertrand Debate': A Historical Perspective," History of Political Economy (1992) 24, pp. 623-656. 